\title{
Design And Build Of Gabah Processing Machine 5 Kg Capacity Transmission System
}

\section{Rancang Bangun Mesin Pengolah Gabah Sistem Transmisi Kapasitas $5 \mathrm{Kg}$}

\author{
Anggoro Dwi Koencoro ${ }^{1}$, Hesti Istiqlaliyah ${ }^{2}$ \\ \{anggorodwi.k@gmail.com, hestiisti@unpkediri.ac.id\} \\ ${ }^{1,2}$ Jurusan Teknik Mesin, Fakultas Teknik, Universitas Nusantara PGRI Kediri
}

\begin{abstract}
Grain processing machinesis a machine designed to improve map welfareni in the district area Nganjuk. This engine component containsri of the paring system,separator system,transmission systemand order. The transmission part serves totransmits the rotation of the drive motor to the driven mechanism through the pully and $v$ belt. This machine has a capacity of $5 \mathrm{~kg}$ at a time.The discussion focused on the transmission system and frame. Main powerin the form of an electric motorto be transmittedusing pulleys and V-belt. Using motor 0.75HP with a motor rotation of 1400 rpm on the main motor. Transmi typesi used pulleys and belts-v, with belt type A. The drive pulley on the motor is $75 \mathrm{~mm}$,puli on a $75 \mathrm{~mm}$ grinder.
\end{abstract}

Key words - Component; Transmission System.

Abstrak. Mesin pengolah gabah adalah sebuah mesin yang dibuat untuk meningkatkan kesejahteraan petani di daerah parang Kabupaten Nganjuk. Komponen mesin ini terdiri dari sistem pengupas, sistem pemisah, sistem transmisi dan rangka. Bagian transmisi berfungsi untuk mentransmisikan putaran dari motor penggerak ke mekanisme yang di gerakan melalui pully dan v-belt. Mesin ini mempunyai kapasitas $5 \mathrm{~kg}$ sekali proses. Pembahasan yang dikhusukan rangka dan sistem transmisi. Daya utama berupa motor listrik yang akan ditransmisikan menggunakan puli dan sabuk-V. Menggunakan motor 0.75 HP dengan putaran motor 1400 rpm pada motor utama, Jenis transmisi yang digunakan puli dan sabuk-v, dengan tipe sabuk A. Besar puli penggerak pada motor $75 \mathrm{~mm}$, puli pada penggiling $75 \mathrm{~mm}$.

Kata kunci - Komponen; Sistem Transmisi.

\section{PENDAHULUAN}

Padi merupakan jenis tanaman yang sering ditemui khusunya di daerah Wilangan Kabupaten Nganjuk. Usia tanaman padi berlangsung hingga tiga bulan, yang kemudian diolah dan dijadikan bahan pangan. Pada saat ini petani tidak mengolah padi menjadi bahan pangan akan tetapi padi langsung dijual, padahal nilai jual padi sebelum diolah dan sesudah diolah berbeda jauh. Hal ini disebabkan oleh minimnya mesin pengolah padi beserta biaya yang dikeluarkan. Dengan adanya fenomena tersebut, perlu diancang suatu teknologi untuk mengatasi hal tersebut. Salah satu penanganan masalah tersebut dengan dirancangnya mesin pengolah padi. Pengolah padi merupakan salah satu rangkaian utama kegiatan penanganan pasca panen. Teknologi pengolah gabah ini sangat berpengaruh besar dalam menentukan mutu beras yang dihasilkan. Mesin ini terdiri dari rangka, sistem penggerak, sistem pengelupas, dan sistem pengayak. Pengelupas gabah sangat penting dalam mengkonversi gabah menjadi beras yang telah siap diolah untuk konsumsi maupun disimpan yang akan digunakan sebagai cadangan pangan. Hasil dari penggilingan gabah erat kaitannya dengan karakteristik gabah, karena dalam pengolahan sebenarnya mengolah butiran-butiran gabah menjadi beras puti. Butiran-butiran gabah yang mengandung berbagai bahan lain/kotoran perlu di saring atau diayak untuk menghasilkan pengolahan yang baik. Sistem transmisi adalah bagian penting dari mesin ini, tanpa adanya hal tersebut mesin tidak akan bisa bergerak.

Sistem transmisi berguna untuk merubah torsi, arah dan kecepatan agar sesuai kebutuhan. Perubahan torsi digunakan untuk merubah torsi besar menjadi kecil dan begitu pula sebaliknya. Perubahan kecepatan digunakan untuk merubah kecepatan tinggi menuju kecepatan rendah dan begitu pula sebaliknya. Di harapkan pemilihan jenis transmisi dan perubahan kecepatan dapat dipilih dengan tepat sebagaimana dengan kebutuhan yang dibutuhkan. Diharapkan 
Procedia of Engineering and Life Science Vol. 1. No. 1 March 2021

Seminar Nasional \& Call Paper Fakultas Sains dan Teknologi (SENASAINS 1 ${ }^{\text {st }}$ )

Universitas Muhammadiyah Sidoarjo

dengan dirancangnya bagian sistem sistem transmisi dapat membantu pembuatan mesin pengolah gabah ini agar menjadi lebih baik lagi.

Dengan dirancangya mesin pengolah gabah kapasitas $5 \mathrm{~kg}$ ini dapat mempermudah petani khusunya di daerah wilangan untuk mengolah gabah menjadi beras. Selain itu dapat meningkatkan nilai jual pada gabah, karena tidak lagi berwujud gabah akan tetapi bahan pokok yaitu beras.

\section{METODE PENELITIAN}

Pembuatan rancang bangun mesin pengolah gabah dilakukan dirumah saya sendiri pada bulan November Desember 2020. Bahan pembuatan yang digunakan pada rancang bangun mesin pengolah gabah terdapat pada tabel 1.

Tabel 1. Bahan yang digunakan pada rancang bangun mesin pengolah gaba

\begin{tabular}{|l|l|l|}
\hline No & Nama Bahan & Spesifikasi \\
\hline 1 & Besi hollow & $30 \times 30 \times 1 \mathrm{~mm}$ \\
\hline 2 & Mur dan Baut & $6 \mathrm{~mm}$ dan $8 \mathrm{~mm}$ \\
\hline 3 & Plat Besi & $1,2 \mathrm{~mm}$ \\
\hline 4 & Plat seng & $0,7 \mathrm{~mm}$ \\
\hline 5 & v-belt & A-61 \\
\hline
\end{tabular}

Adapapun alat yang digunakan untuk pembuatan rancang bangun mesin pengolah gabah terdapat pada tabel 2.

Tabel 2. Alat yang digunakan pada rancang bangun mesin pengolah gabah

\begin{tabular}{|l|l|l|}
\hline No & Nama Alat & Spesifikasi \\
\hline 1 & Mesin las & $900 \mathrm{Watt}$ \\
\hline 2 & Gerinda tangan & 400Watt \\
\hline 3 & mesin bubut & - \\
\hline 4 & Bor tangan & $10 \mathrm{~mm}$ dan $12 \mathrm{~mm}$ \\
\hline 5 & Kunci pas ring & $2 \mathrm{HP}$ \\
\hline 6 & kompresos & \\
\hline
\end{tabular}

Dalam pembuatan mesin pengolah gabah dapat dilakukan dengan diagram alir yang tertera pada gambar 1.
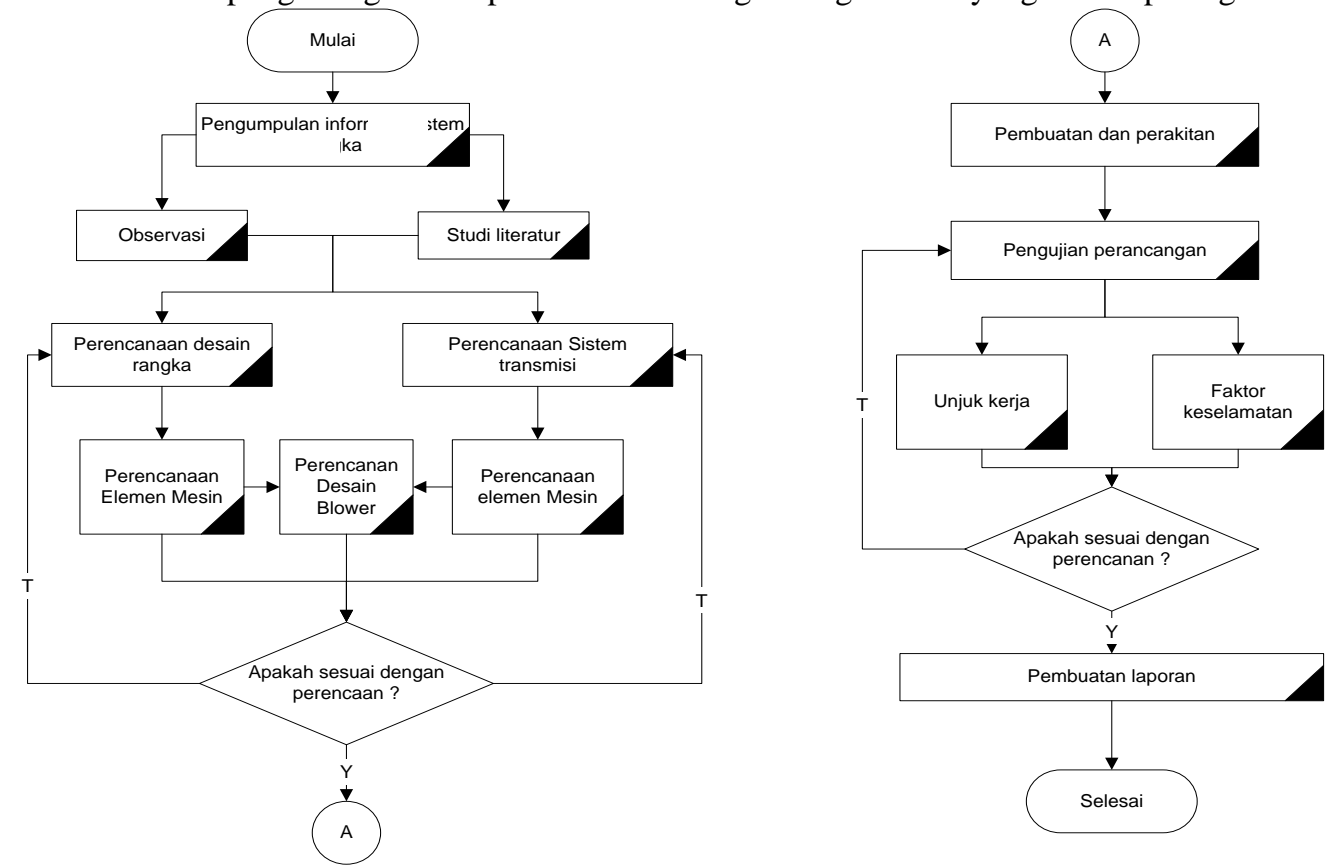

Gambar 1. Diagram alir pembuatan mesin pengolah gabah

Adapun terdapat langkah - langkah pelaksanaan ini sebagai berikut. 
Pengumpulan informasi

Pengumpulan data informasi dilakukan dengan langkah sebagai berikut:

1) Studi literatur berupa buku pustaka, jurnal, artikel yang dilaksanakan di perpustakaan Universitas Nusantara PGRI Kediri.

2) Selain itu pengumpulan data juga dilakukan dengan cara observasi secara langsung. Obeservasi dilakukan di tempat para petani padi di Wilangan Kabupaten Nganjuk. Di tempat tersebut proses pngupasan menggunakan mesin pengupas keliling dan itu pun belom tentu kpan datangnya soalnya armada mesin masih sedikit, dan sistem pemisah masih menggunakan manual dengan tenaga manusia. Oleh sebab itu penulis mempunyai ide untuk membuat mesin pengolah gabah tersebut.

\section{a. Perencanaan desain}

Untuk sistem rangka diharapkan dapat menahan komponen diatasnya (motor listrik, poros, sistem pengupas, sistem penggiling, sistem pengayak) dan tidak boleh terjadi patah atau deformasi pada kerangka. Besi hollow 30x30x2mm dipilih untuk bahan pembuatan rangka karen mudah didapat, murah dan mudah di aplikasikan. Berdasarkan observasi didapatkan desain pada mesin pengolah gabah otomatis adalah sebagai berikut :

1) Prinsip kerja dari mesin pengolah gabah semi otamati kapasitas $5 \mathrm{~kg}$ adalah memanfatkan tenaga putaran untuk mengupas gabah dan untuk memutar sistem poliser, sistem penggiling kulit beras.

2) Cara kerja dari mesin pengolah gabah otomatis kapasitas $5 \mathrm{~kg}$ adalah gabah di masukan pada tempat yang sudah disediakan gabah masuk pada sistem pengupas turun untuk memisahkan kulit beras dengan beras dengan memanfaatkan putaran vakum. Selanjutnya beras masuk ke sistem pengayak untuk memisahkan kotoran, beras dan menir.

3) Dari perencanaan desain didapatperancanaan gambar mesi pengolah gabah otomatis kapasitas $5 \mathrm{~kg}$ yang ditunjukan pada 3.2. berikut :

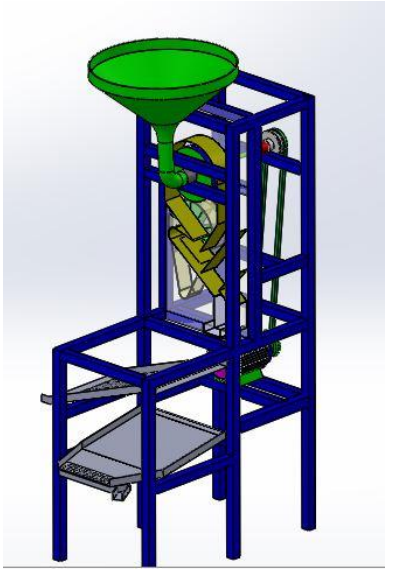

Gambar 2. Desain mesin pengolah gabah

Desain ini yang dibuat berupa mesin pengolah gabah dengan dimensi : T. $136 \mathrm{~cm}$ x L. $45 \mathrm{~cm}$ x P.100 cm. Gambar desain rancangan untuk tampak depan dapat dilihat (gambar 3.a), atas (gambar 3.b), belakang (gambar 3.c), samping (gambar 3.d)

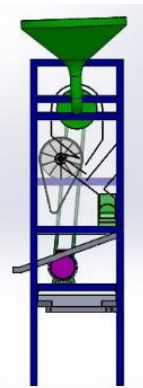

(a)

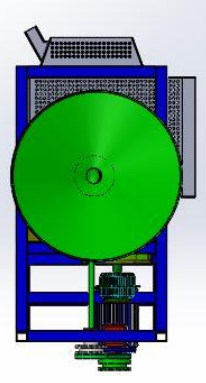

(b)

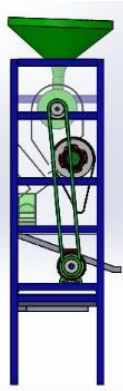

(c)

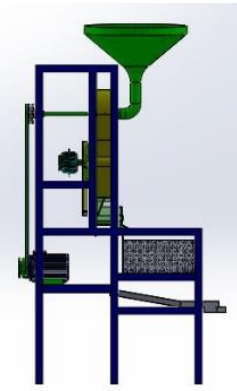

(d)

Gambar 3. (a) Tampak depan, (b) tampak atas, (c) tampak belakang, (d) tampak samping

\section{b. Perencanaan elemen}

Langkah langkah perencanaan elemen mesin pada mesin pengolah gabah kapasitas $5 \mathrm{~kg}$ adalah sebagai berikut : 
Procedia of Engineering and Life Science Vol. 1. No. 1 March 2021

Seminar Nasional \& Call Paper Fakultas Sains dan Teknologi (SENASAINS 1 ${ }^{\text {st }}$ )

Universitas Muhammadiyah Sidoarjo

1) Menentukan diameter puli dan panjang sabuk-v

2) Motor listrik

3) Rangka

4) Sambungan las

c. Pembuatan dan perakitan

Pembuatan rangka mesin pengolah gabah otomatis kapasitas $5 \mathrm{~kg}$ ini menggunakan besi hollow agar kuat menahan beban yang diterima oleh rangka, dan mudah untuk di sambung. Pembuatan rangka ini juga harus sesuai dengan yang direncanakan dan yang digambar. Proses untuk pembuatan rangka ini ialah memotong dan mengukur bahan yang digunakan untuk membuatan rangka. Bahan yang digunakan besi hollow 30mmx30mmx1mm pada rangka.

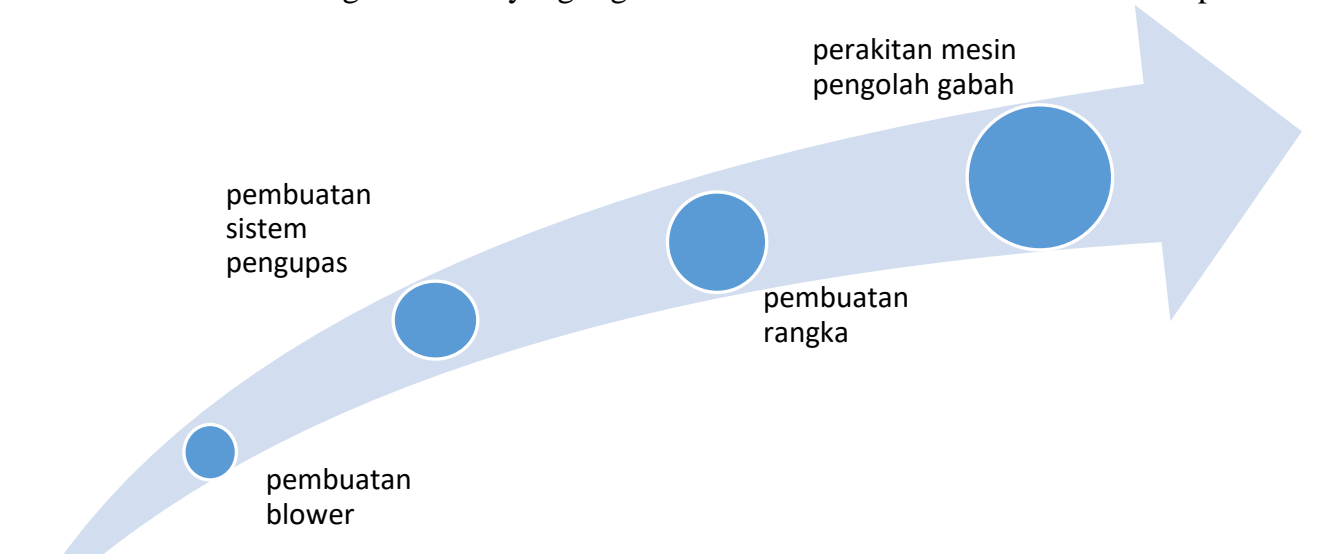

Pembuatan mesin dimulai dari penyiapan alat dan bahan, pembutan sistem blower, pembuatan sistem pengupas, pembuatan rangka, memasang dudukan mesin, pemasangan semua sistem, pemasangan bearing, pemasangan pilley

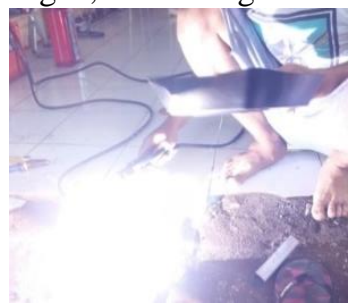

(a)

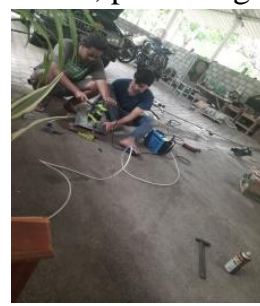

(b)

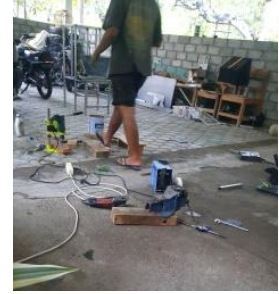

(c)

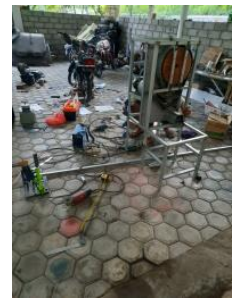

(d)

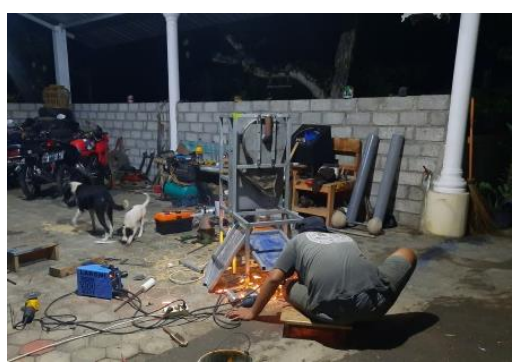

(e)

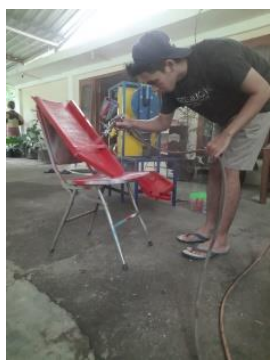

(f)

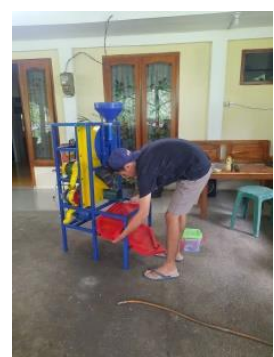

(g)

Gambar 5. Proses pembuatan mesin. (a) proses pengelasan, (b) pembuatan pengayak, (c) pembuatan rangka, (d) pemasangan pengupas, (e) pengelasan dudukan pengayak, (f) proses finising pengecetan, $(\mathrm{g})$ perakitan Mesin pengolah gabah dapat dilihat pada gambar 6. 


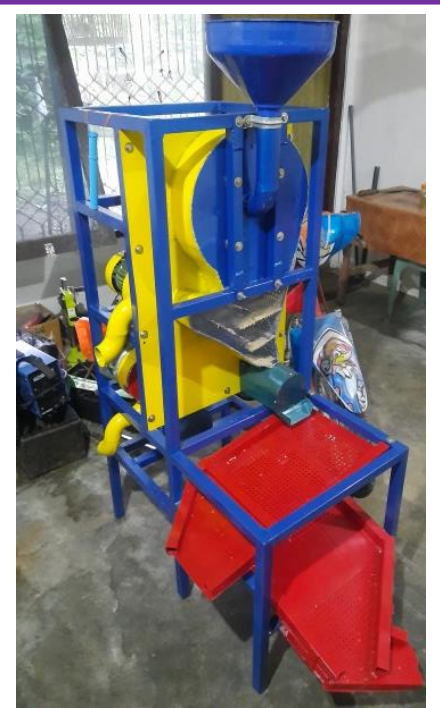

Gambar 6. Mesin pengolah gabah kapasitas $5 \mathrm{~kg}$

\section{HASIL DAN PEMBAHASAN}

\section{A. Komponen- komponen utama alat}

Mesin pengolah gabah memiliki beberapa komponen yang terdapat pada gambar (gambar 7 ) yang digunakan adalah :

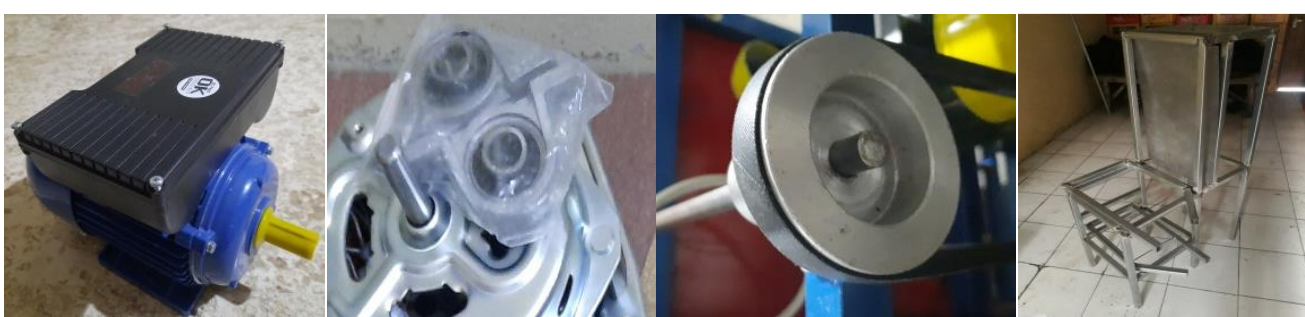

(a) (c)

Gambar 7. Komponen-komponen utama. (a) motor listrik, (b) bearing, (c) pully, (d) rangka penompang

1. Motor Listrik

Motor listrik yang digunakan $0,75 \mathrm{HP}$ sebagai penggerak utama

2. Bearing

Merupakan suatu komponen untuk mengurang gesekan antar benda atau alat saat putaran, sehingga membuat putaran roda dan beban yang dibutar dapat berputar dengan lancar.

3. Pully

Merupakan alat yang digunakan untuk mengubah arah dari putaran tinggi ke putaran lebih rendah begituga sebaliknya.

4. Kerangka

Merupakan alat untuk menopang semua komponen yang ada pada mesin pengolah gabah ini

\section{B. Uji coba mesin}

Mesin di uji untuk mengetahui kemapuan suatu mesin dalam hal fungsi komponen, ketahanan dan keselamatan kerja, uji coba mesin ini dilakukan dengan memasukan butiran gabah yang sudah dijemur sampai kering lalu dimasukan pada corong yang sudah ada pada mesin pengolah gabah. 


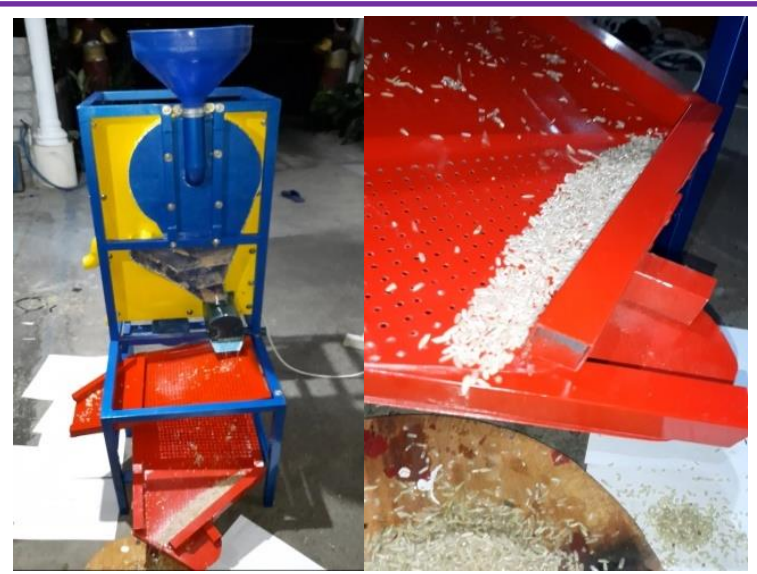

Gambar 8. Uji coba alat

Gambar 8 menunjukan bahwa mesin sedang mengolah gabah menjadi beras, hasil yang diperolah gabah dapat terkelupas dengan baik dan kulit gabah dapat terpisah dengan baik . hasil pengujian mesin diperoleh data pada tabel 3.

Tabel 3. Hasil pengujian mesin

\begin{tabular}{|r|c|c|c|}
\hline No & $\begin{array}{c}\text { Produksi } \\
(\mathrm{kg})\end{array}$ & $\begin{array}{c}\text { Waktu } \\
(\text { Menit })\end{array}$ & $\begin{array}{c}\text { Berat } \\
\text { bahan akhir } \\
(\mathrm{kg})\end{array}$ \\
\hline 1 & $1 \mathrm{~kg}$ & $2 \mathrm{mnt}$ & $0,6 \mathrm{~kg}$ \\
\hline 2 & $5 \mathrm{~kg}$ & $10 \mathrm{mnt}$ & $2,5 \mathrm{~kg}$ \\
\hline
\end{tabular}

Hasil dapat dilihatkan bahwa mesin pengolah gabah ini dalam $1 \mathrm{~kg}$ membutuhkan waktu selama $2 \mathrm{mnt}$. Sehingga untuk $5 \mathrm{~kg}$ gabah memerlukan waktu selama $10 \mathrm{mnt}$ dan membutuhkan listrik $1.5 \mathrm{kwh}$ atau 1500 watt. Mesin pengolah gabah ini sehari mampu bekerja selama 2 jam.

\section{KESIMPULAN}

Berdasarkan hasil penelitian ini, maka dapat disimpulkan yaitu : Mesin pengolah gabah telah bekerja secara maksimal dengan jumplah rata-rata dapat beroprasi $0.5 \mathrm{~kg} / \mathrm{menit}$. Mesin pengolah gabah ini memiliki 2 motor listrik, yaitu mesin pengupas gabah dan motor listrik untuk memutar blower sebagai pemisah kulit gabah dengan beras.

\section{REFERENSI}

[1] Paktani S. (2018),Fakta tentang padi (beras) di indonesia. paktanidigital.comartikel/fakta-tentang-beras-diindonesia/\#XOLa2lcxd-E,Diakses tanggal 13 februari 2019

[2] Sularso Dan Suga. Kiyokatsu. (2004). Dasar Perencanaan Dan Pemilihan Elemen Mesin. Jakarta: Pradnya Paramita

[3] Ramli D.(2018) Tegangan Normal Dan Tegangan Geser Pada Kontruksi. https://dhamarar.blogspot.com/2018/02/tegangan-normal-dan-tegangan-geser-pada.html. Diakses tanggal 8 februari 2019

[4] arry.C.W(2019). Hollow Structural Sections. http://www.cwcarry.com/product/HSS. Diakses tanggal 08 maret 2019 